\title{
DIVERSITAS PLANKTON DAN KUALITAS PERAIRAN WADUK DARMA KABUPATEN KUNINGAN JAWA BARAT
}

\author{
[Plankton diversity and water quality of Darma reservoir water \\ of Kuningan District West Java] \\ O.D Soebhakti Hasan ${ }^{\bowtie}$, Dinno Sudinno, Sopiyan Danapraja, \\ Endang Suhaedy, Iin Siti Djunnaidah, \\ Sekolah Tinggi Perikanan,Jurusan Penyuluhan Perikanan \\ Jalan Cikaret No. 2 Bogor, Jawa Barat \\ Diterima: 10 Oktober 2017; Disetujui: 22 November 2017
}

\begin{abstract}
ABSTRAK
Penelitian tentang "Diversitas Plankton dan Kualitas Perairan Waduk Darma" telah dilaksanakan pada Bulan Agustus 2017. tujuan dari penelitian ini untuk mengetahui diversitas plankton dan kualitas air waduk Darma. Sampel diambil dari 3 stasiun pengamatan. Titik pengambilan sampel ditentukan dengan metode purposive sampling. Hasil penelitian didapatkan, Genera fitoplankton yang ditemukan di Waduk Darma sebanyak 19-32 genera yang mewakili 5 kelas, yaitu Chlorophyceae, Cyanophyceae, Bacillariophyceae, Dinophyceae dan Euglenaphyceae. Serta Genera Zooplankton yang ditemukan di Waduk Darma sebanyak 12-15 genera yang mewakili 3 kelas, yaitu Rotifera, Ciliata dan Malacostraca. Indeks diversitas fitoplankton berkisar antara 0,367 - 1,376 dan diversitas zooplankton berkisar antara 1,379 - 2,023. Hal ini menunjukkan bahwa waduk Darma memiliki tingkat keanekaragaman rendah.
\end{abstract}

Kata kunci: Diversitas plankton, waduk Darma

\begin{abstract}
Research on "Plankton Diversity and Quality of Darma Reservoir Water" was conducted in August 2017. The purpose of this research is to know the diversity of plankton and water quality of Darma reservoir. Samples were taken from 3 observation stations. The sampling point was determined by the purposive sampling method. The results of the study were Genera phytoplankton found in Darma Reservoir of 19-32 genera representing 5 classes, namely Chlorophyceae, Cyanophyceae, Bacillariophyceae, Dinophyceae and Euglenaphyceae. As well as Genera Zooplankton found in Reservoir Darma as many as 12-15 genera representing 3 classes, namely Rotifera, Ciliata and Malacostraca. The phytoplankton diversity index ranged from $0.367-1.376$ and zooplankton diversity ranged from 1.379 - 2.023. This suggests that Darma reservoirs have low levels of diversity.

Keywords: Plankton Diversity, Darma Reservoir

\section{PENDAHULUAN}

Waduk merupakan salah satu perairan umum yang merupakan perairan buatan (artificial water-bodies), dibuat dengan cara membendung badan sungai tertentu (Wiadnya, et al., 1993). Pembuatan waduk pada umumnya bertujuan untuk,

PLTA, pengendali banjir, , sebagai habitat berbagai jenis organisme air, sebagai sumber air minum bagi masyarakat sekitarnya, sebagai sumber air untuk kegiatan pertanian dan budidaya perikanan serta untuk menunjang berbagai jenis industri, irigasi dan pariwisata

Di dalam perairan terdapat jasadjasad hidup, dan salah satunya adalah
\end{abstract}


plankton. Plankton adalah istilah umum untuk biota yang hanyut, melayang atau mengambang di dalam air secara bebas, kemampuan geraknya kalaupun ada sangat terbatas atau dengan kata lain penyebarannya lebih banyak diatur oleh pergerakan air seperti arus, gelombang dan sebagainya (Nontji, 2006). Plankton yang merupakan tumbuhan mikroskopis disebut fitoplankton. Fitoplankton sebagian besar merupakan organisme autotropik dan menjadi produsen primer dari bahan organik pada habitat akuatik. Komponen lain dari plankton adalah binatang heterotropik yang disebut zooplankton. Fitoplankton dapat berperan sebagai salah satu dari parameter ekologi yang dapat menggambarkan kondisi kualitas perairan.

Fitoplankton merupakan dasar produsen primer mata rantai makanan di

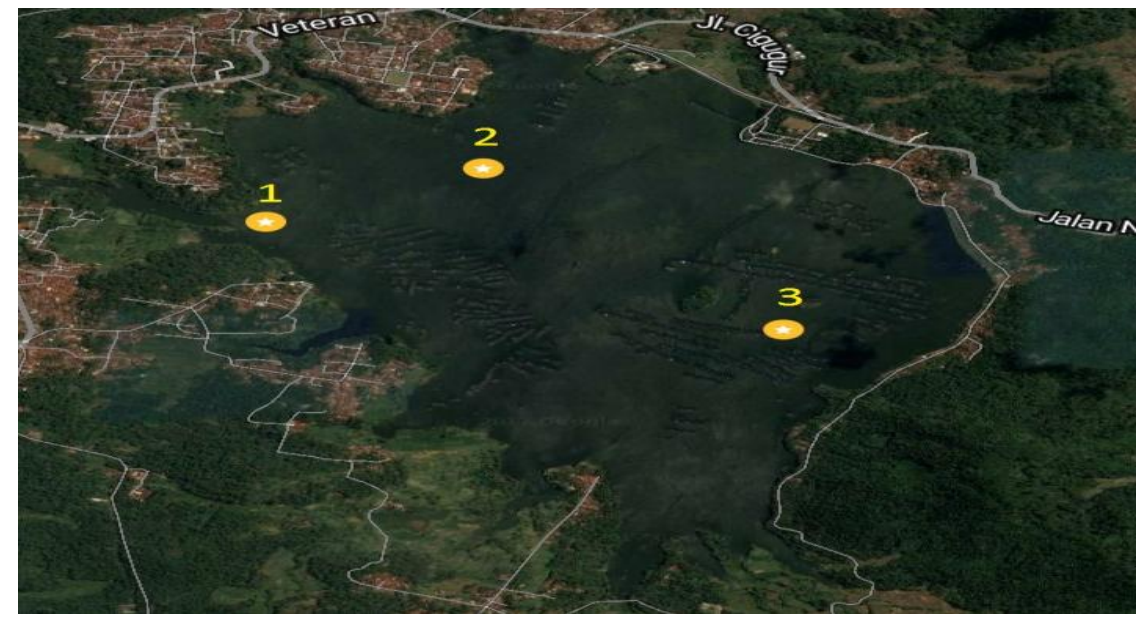

Gambar 1. Lokasi Penelitian.

1. Stasiun 1 yaitu sekitar sungai Cisanggarung (Inlet)

2. Stasiun 2 yaitu Sekitar Outlet

3. Stasiun 3 yaitu sekitar area Karamba Jaring Apung

alam perairan seban masukan

perairan. Keberadaannya di yang ada akan menyebabkan perubahan perairan dapat menggambarkan status 
pada komposisi, kelimpahan dan distribusi dari komunitas fitoplankton.

Keberadaan zooplankton sangat dipengaruhi oleh adanya fitoplankton, karena fitoplankton merupakan sumber makanan bagi zooplankton. Selain dipengaruhi oleh fitoplankton, kelimpahan zooplankton juga dipengaruhi oleh kualitas air sebagai pendukung kehidupan plankton.

Waduk Darma merupakan waduk irigasi yang terletak di Kabupaten Kuningan dengan luas genangan 400 ha ,waduk Darma ini merupakan sumber daya air yang mempunyai nilai yang sangat penting ditinjau dari fungsi ekologis serta fungsi ekonomis. Waduk Darma mulai dibangun pada Tahun 1958. Selain sebagai sumber air minum, Waduk Darma juga berfungsi sebagai sumber air untuk pertanian dan perikanan serta sebagai daerah pariwisata. (Nur Sa'ban, 2008). Stabilitas suatu ekosistem berkorelasi positif lebih kuat dengan keanekaragaman jenis dari pada dengan produktivitasnya. Untuk itu diperlukan suatu pemantauan ekosistem yang baik, agar stabilitas ekosistem senantiasa tetap terjaga. Hal ini dapat dilaksanakan dengan mengupayakan tetap tingginya nilai indeks diversitas komunitas menjadi pendukung ekosistem tersebut . Penelitian ini bertujuan untuk mengetahui diversitas kondisi plankton dan kualitas air waduk Darma

\section{METODE PENELITIAN}

Penelitian ini dilakukan pada Bulan Agustus-September 2017, stasiun penelitian dibagi menjadi tiga stasiun yang mewakili perairan Waduk Darma, Jawa Barat ( Gambar 1 ).

Sampel air diambil dengan menggunakan kemmerer water sampler Kemudian sampel air disaring dengan menggunakan plankton net No. 25 dengan ukuran mata jaring $60 \mu \mathrm{m}$ dan diawetkan dengan larutan lugol sebanyak 5 tetes. Analisis sampel plankton dilakukan di laboratorium plankton Institut Pertanian Bogor dengan menggunakan buku identifikasi untuk plankton air tawar kelimpahan plankton dihitung dengan menggunakan metode pencacahan (sensusSRC). Beberapa indeks biologi plankton yang dianalisis adalah indeks keanekaragaman Shannon, indeks keseragaman atau Evenness (e), dan indeks dominansi.

Indeks Keanekaragaman digunakan untuk melihat tingkat stabilitas suatu komunitas atau menunjukkan kondisi struktur komunitas dari keanekaragaman jumlah jenis organisme yang terdapat dalam suatu area. Nilai keanekaragaman jenis yang ada dalam komunitas plankton diperoleh dari hasil perhitungan berdasar146 
kan modifikasi Indeks Shannon-Wiener (Odum 1971), yaitu:

$$
: \mathrm{H}^{\prime}=-\sum_{\mathbf{i}=\mathbf{1}}^{\mathrm{n}} P i \ln P i
$$

Keterangan :

$\mathrm{H}^{\prime}$ : Indeks keanekaragaman

$p i: n i$ / N (proporsi jenis ke-i)

$n i$ : jumlah individu jenis ke- $i$

$\mathrm{N}$ : jumlah total individu

Mason (1981), nilai indeks keanekaragaman populasi dapat menggambarkan kondisi perairan. Kriteria indeks keanekaragaman tersebut diklasifikasikan sebagai berikut.

H'<2,3026 : Keanekaragaman rendah, penyebaran jumlah individu tiap genus rendah dan kestabilan komunitas rendah. Komunitas mengalami gangguan faktor lingkungan.

$2,3026<\mathrm{H}^{\prime}<6,9078$ : Keanekaragaman sedang, penyebaran jumlah individu tiap genus sedang dan kestabilan komunitas sedang. Komunitas mudah berubah.

H'>6,9078 : Keanekaragaman tinggi, penyebaran jumlah individu tiap genus tinggi dan kestabilan komunitas tinggi.
Faktor lingkungan yang baik untuk semua jenis dalam habitat.

Indeks Ekuitabilitas (E) Untuk mengetahui sebaran ataupun distribusi kelimpahan antar takson dalam komunitas yang disebut juga sebagai indeks keseragaman. Rumus indeks keseragaman (Brower dan Zar 1990) dinyatakan sebagai berikut.

\section{$\mathbf{E}=\mathbf{H}^{\prime} /$ Hmaks}

dimana :

$H^{\prime}=$ Indeks diversitas Shannon-Wienner

$\mathrm{H}$ max = Indeks diversitas maximum, yang nilainya sama dengan $\mathrm{Ln} \mathrm{S}$ (dimana $\mathrm{S}$ banyaknya spesies).

Nilai indeks keseragaman (E) berkisar antara 0-1 (Michael, 1984). Semakin kecil nilai E, semakin kecil pula keseragaman populasinya. Artinya penyebaran individu tiap jenis tidak merata atau ada kecenderungan satu genus mendominasi. Sebaliknya, apabila nilai E mendekati 1 maka penyebaran individu tiap jenis cenderung merata atau memiliki tingkat keseragaman yang tinggi

Kriteria:

$0<\mathrm{E}<0,4 \quad$ : Keseragaman rendah 
Tabel 1. Komposisi Fitoplankton pada Stasiun 1

\begin{tabular}{|c|c|c|c|}
\hline Organisme & A-1 & A-2 & A-3 \\
\hline \multicolumn{4}{|l|}{ BACILLARIOPHYCEAE } \\
\hline Navicula sp. & 7.600 & 2.600 & 4.200 \\
\hline Nitzschia sp. & 391.000 & 409.800 & 259.000 \\
\hline Synedra sp. & 3.400 & 7.400 & 3.000 \\
\hline Tabellaria sp. & 1.400 & 400 & 0 \\
\hline Diatoma sp. & 7.800 & 3.600 & 3.600 \\
\hline Eunotia sp. & 1.200 & 400 & 0 \\
\hline Gyrosigma sp. & 200 & 0 & 0 \\
\hline Fragilaria sp. & 6.600 & 0 & 0 \\
\hline Achnanthes sp. & 0 & 400 & 0 \\
\hline Melosira sp. & 0 & 1.600 & 2.000 \\
\hline Surivella sp. & 3.200 & 200 & 3.000 \\
\hline Pleurosigma sp. & 0 & 0 & 200 \\
\hline Amphora sp. & 0 & 0 & 400 \\
\hline Cocconeis sp. & 0 & 0 & 800 \\
\hline Bacillaria sp. & 0 & 5.600 & 3.600 \\
\hline \multicolumn{4}{|l|}{ CHLOROPHYCEAE } \\
\hline Staurastrum sp. & 2.000 & 0 & 0 \\
\hline Ankistrodesmus sp. & 3.000 & 1.600 & 0 \\
\hline Pediastmum sp. & 7.400 & 5.600 & 8.000 \\
\hline Scenedesmus sp. & 20.800 & 12.400 & 15.800 \\
\hline Clasterium sp. & 5.200 & 0 & 3.400 \\
\hline Cosmarium sp. & 2.400 & 1.000 & 800 \\
\hline Cnucigenia sp. & 9.600 & 20.000 & 13.600 \\
\hline Microspora sp. & 21.600 & 7.600 & 0 \\
\hline \multicolumn{4}{|l|}{ CYANOPHYCEAE } \\
\hline Spinulina sp. & 14.400 & 0 & 4.800 \\
\hline Oscillatoria sp. & 0 & 0 & 24.800 \\
\hline Anabaena sp. & 7.000 & 0 & 1.800 \\
\hline Microcystis sp. & 9.600 & 0 & 0 \\
\hline $\begin{array}{l}\text { Aphanizomenon sp. } \\
\text { DINOPHYCEAE }\end{array}$ & 7.000 & 1.200 & 0 \\
\hline Peridinium sp. & 13.800 & 6.200 & 7.200 \\
\hline Ceratium sp. & 0 & 0 & 2.200 \\
\hline \multicolumn{4}{|l|}{ EUGLENOPHYCEAE } \\
\hline Phacus sp. & 0 & 200 & 200 \\
\hline Euglena sp. & 0 & 200 & 0 \\
\hline
\end{tabular}

$0,4<\mathrm{E}<0,6:$ Keseragaman sedang

E $>0,6 \quad$ : Keseragaman tinggi

indeks dominansi (Odum 1971)

digunakan untuk mengetahui ada tidaknya

genus tertentu yang mendominasi suatu

komunitas. Nilai indeks dominansi

dihitung dengan rumus sebagai berikut.

S

$$
\begin{gathered}
\mathrm{C}=\sum[\mathrm{ni} / \mathbf{N}]^{2} \\
\mathbf{i}=\mathbf{1}
\end{gathered}
$$

Dengan ketentuan :

$\mathrm{C}=$ Indeks dominansi Simpson

ni $=$ Jumlah individu ke-i

$\mathrm{N}=$ Jumlah total individu

$\mathrm{s}=$ Jumlah jenis

\section{HASIL DAN PEMBAHASAN}

A. Komposisi Jenis plankton di Perairan Keanekaragaman adalah Jumlah total spesies dalam suatu area atau sebagai 
Tabel 2. Komposisi Fitoplankton pada Stasiun 2

\begin{tabular}{|c|c|c|c|}
\hline Organisme & B-1 & B-2 & B-3 \\
\hline \multicolumn{4}{|l|}{ BACILLARIOPHYCEAE } \\
\hline Navicula sp. & 1.600 & 1.200 & 1.000 \\
\hline Nitzschia sp. & 565.000 & 460.800 & 384.000 \\
\hline Synedra sp. & 0 & 200 & 0 \\
\hline Diatoma sp. & 6.400 & 3.200 & 2.400 \\
\hline Eunotia sp. & 800 & 3.800 & 3.800 \\
\hline Coscinodiscus sp. & 400 & 0 & 400 \\
\hline Cyclotella sp. & 7.400 & 5.200 & 4.600 \\
\hline Frustulia sp. & 400 & 0 & 0 \\
\hline \multicolumn{4}{|l|}{ CHLOROPHYCEAE } \\
\hline Staurastrum sp. & 2.200 & 3.200 & 7.800 \\
\hline Ankistrodesmus sp. & 0 & 200 & 200 \\
\hline Pediastrum sp. & 0 & 5.800 & 6.800 \\
\hline Scenedesmus sp. & 4.200 & 5.600 & 4.800 \\
\hline Spirogyra sp. & 0 & 2.400 & 1.800 \\
\hline Closterium sp. & 0 & 200 & 200 \\
\hline Micrasterias sp. & 0 & 400 & 0 \\
\hline Coscinodiscus $s p$. & 0 & 600 & 0 \\
\hline Cosmarium sp. & 1.200 & 2.400 & 1.600 \\
\hline Grucigenia sp. & 15.200 & 20.000 & 17.600 \\
\hline Microspora sp. & 16.600 & 7.200 & 14.600 \\
\hline Ulothrix sp. & 0 & 1.600 & 0 \\
\hline \multicolumn{4}{|l|}{ CYANOPHYCEAE } \\
\hline Spirulina sp. & 0 & 33.600 & 26.400 \\
\hline Oscillatoria sp. & 55.800 & 37.200 & 49.600 \\
\hline Coelosphaerium sp. & 0 & 1.600 & 1.200 \\
\hline \multicolumn{4}{|l|}{ DINOPHYCEAE } \\
\hline Peridinium sp. & 0 & 400 & 0 \\
\hline Ceratium sp. & 200 & 1.000 & 1.200 \\
\hline EUGLENOPHYCEAE & & & \\
\hline
\end{tabular}

jumlah spesies antar jumlah total individu dari spesies yang ada di dalam suatu komunitas (Michael, 1984). Keanekaragaman memegang peranan vital dari kekayaan alam di bumi ini. Keanakaragaman memelihara kualitas air dan udara serta menjaga kesuburan tanah dengan pembusukan dan mendaur ulang sisa buangan.dalam bidang perikanan

\section{Jenis - jenis Fitoplankton yang ditemukan pada Waduk Darma}

Genera fitoplankton yang ditemukan di stasiun 1 Waduk Darma selama

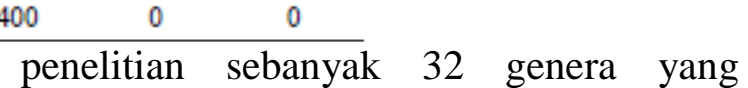
mewakili 5 kelas, yaitu Chlorophyceae, Cyanophyceae, Bacillariophyceae, Dinophyceae dan Euglenaphyceae. Genera fitoplankton dari kelas Bacillariophyceae merupakan genera yang paling banyak ditemukan. Jumlah masing-masing genera perkelas secara berturut-turut adalah 15 genera Bacillariophyceae, 8 genera Chlorophyceae, 5 genera Cyanophyceae, 2 genera Dinophyceae dan 2 genera Euglenaphyceae. Kelimpahan fitoplankton berkisar $362.400-546.200 \mathrm{Sel} / \mathrm{m}^{3}$. 
Tabel 3. Komposisi Fitoplankton pada Stasiun 3

\begin{tabular}{|c|c|c|c|}
\hline Organisme & $c-1$ & $C-2$ & $c-3$ \\
\hline \multicolumn{4}{|l|}{ BACILLARIOPHYCEAE } \\
\hline Navicula sp. & 1.200 & 2.400 & 400 \\
\hline Nitzschia sp. & 957.600 & 952.000 & 939.400 \\
\hline Synedra sp. & 20.400 & 16.000 & 9.400 \\
\hline Tabellaria sp. & 2.800 & 1.200 & 2.400 \\
\hline Diatoma sp. & 1.800 & 2.400 & 2.400 \\
\hline Fragilaria sp. & 12.200 & 12.800 & 15.400 \\
\hline Melosira sp. & 800 & 400 & 800 \\
\hline Pleurosigma sp. & 400 & 0 & 0 \\
\hline Cymbella sp. & 0 & 0 & 400 \\
\hline Bacillaria sp. & 2.200 & 0 & 0 \\
\hline \multicolumn{4}{|l|}{ CHLOROPHYCEAE } \\
\hline Scenedesmus sp. & 400 & 0 & 0 \\
\hline Zygnema sp. & 1.400 & 0 & 0 \\
\hline Stauroneis sp. & 400 & 400 & 0 \\
\hline Gonatozygon sp. & 1.200 & 1.400 & 2.800 \\
\hline Cosmarium sp. & 800 & 0 & 0 \\
\hline Microspora sp. & 0 & 3.000 & 0 \\
\hline \multicolumn{4}{|l|}{ CYANOPHYCEAE } \\
\hline Oscillatoria sp. & 12.400 & 24.800 & 43.400 \\
\hline Phormidium sp. & 7.400 & 1.400 & 1.200 \\
\hline \multicolumn{4}{|l|}{ DINOPHYCEAE } \\
\hline Ceratium sp. & 6.400 & 2.400 & 3.400 \\
\hline
\end{tabular}

Dari Tabel 1 dapat dilihat bahwa dalam struktur komunitas biota yang indeks keanekaragaman fitoplankton diamati tidak terdapat genus yang secara berkisar antara 1,298 - 1,376. Hal ini ekstrim mendominasi genus lainnya.

menunjukkan bahwa stasiun 1 memiliki tingkat keanekaragaman rendah. indeks keseragaman berkisar 0,272 - 0,445 hal ini menunjukkan keseragaman rendah, artinya individu tiap jenis tidak merata atau ada kecenderungan satu genus mendominasi. Nilai indeks dominansi berkisar 0,519 0,709 . Hal ini disebutkan oleh Basmi (2000) bahwa kisaran nilai indeks dominansi mulai dari $0-1$, apabila nilai yang didapatkan mendekati nol berarti di

Genera fitoplankton yang ditemukan di stasiun 2 Waduk Darma selama penelitian sebanyak 26 genera yang mewakili 5 kelas, yaitu Chlorophyceae, Cyanophyceae, Bacillariophyceae, Dinophyceae dan Euglenaphyceae . Genera fitoplankton dari kelas Chlorophyceae merupakan genera yang paling banyak ditemukan. Jumlah masing-masing genera perkelas secara berturut-turut adalah 8 genera Bacillariophyceae , 12 genera

\begin{tabular}{ccc}
\hline Stasiun & Rata-Rata & Kisaran \\
\hline 1 & 1,162 & $1,298-1,376$ \\
2 & 0,978 & $0,726-1,166$ \\
3 & 0,390 & $0,367-0,403$ \\
\hline
\end{tabular}

Tabel 4. Rata - Rata Indeks Diversitas Fitoplankton 
Chlorophyceae, 3 genera Cyanophyceae, 2 genera Dinophyceae dan 1 genera Euglenaphyceae. Kelimpahan fitoplankton berkisar $530.000-677.800 \mathrm{Sel} / \mathrm{m}^{3}$.

Dari Tabel 2 dapat dilihat bahwa indeks keanekaragaman fitoplankton berkisar antara 0,726 - 1,166. Hal ini menunjukkan bahwa stasiun 2 memiliki tingkat keanekaragaman rendah. indeks keseragaman berkisar 0,268 - 0,396 hal ini menunjukkan keseragaman rendah, artinya individu tiap jenis tidak merata atau ada kecenderungan satu genus mendominasi. Nilai indeks dominansi berkisar 0,539 0,703 . Hal ini berarti di dalam struktur komunitas biota yang diamati terdapat genus yang secara ekstrim mendominasi genus lainnya

Genera fitoplankton yang ditemukan di stasiun 3 Waduk Darma selama penelitian sebanyak 19 genera yang
Bacillariophyceae, dan Dinophyceae.

Genera fitoplankton dari kelas Bacillariophyceae merupakan genera yang paling banyak ditemukan. Jumlah masing-masing genera perkelas secara berturut-turut adalah 10 genera Bacillariophyceae, 6 genera Chlorophyceae, 2 genera Cyanophyceae, dan 1 genera Dinophyceae . Kelimpahan fitoplankton berkisar 1.020 .600 1.029.800 Sel $/ \mathrm{m}^{3}$.

Dari Tabel 3 dapat dilihat bahwa indeks keanekaragaman fitoplankton berkisar antara 0,367 - 0,403. Hal ini menunjukkan bahwa stasiun 3 memiliki tingkat keanekaragaman rendah. indeks keseragaman berkisar $0,142-0,161$ hal ini menunjukkan keseragaman rendah, artinya individu tiap jenis tidak merata atau ada kecenderungan satu genus

mendominasi. Nilai indeks dominansi

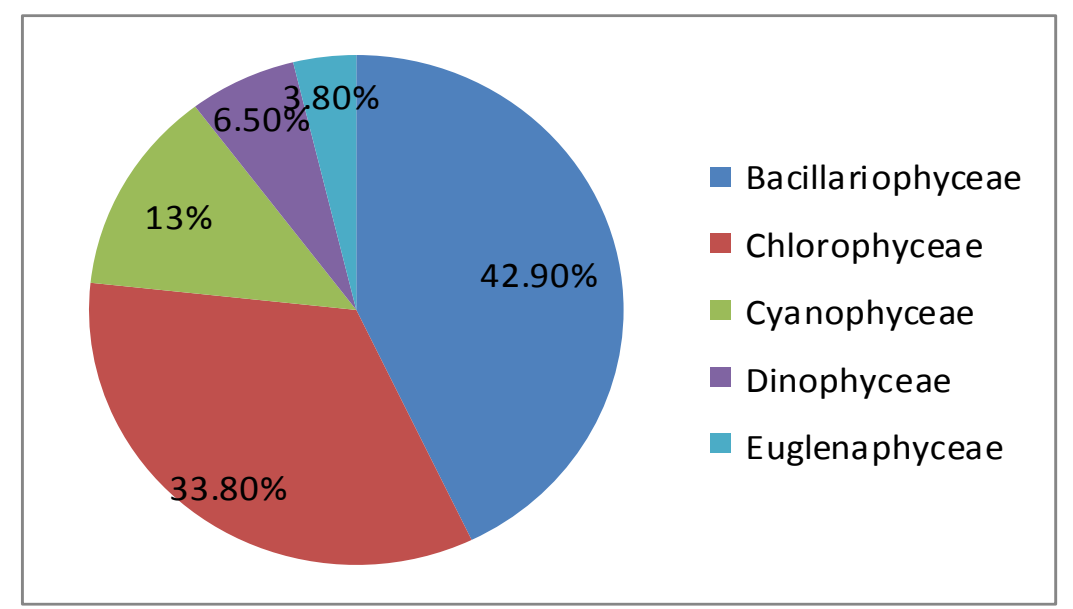

Gambar 2. Persentase Fitoplankton Di Waduk Darma

serarti di

Chlorophyceae,

Cyanophyceae,

dalam struktur komunitas biota yang 
diamati terdapat genus yang secara ekstrim mendominasi genus lainnya

Berdasarkan perhitungan persentase fitoplankton perkelas secara berturut-turut adalah 42,9 \% Bacillariophyceae , 33,8 \% Chlorophyceae, $13 \%$ Cyanophyceae, 6,5 $\%$ Dinophyceae dan 3,8 \% Euglenaphyceae.seperti yang terlihat pada gambar 2

Berdasarkan hasil rata-rata indeks Diversitas (Tabel 4 ), nilai rata rata indeks Diversitas fitoplankton pada stasiun 1,2 dan 3 berkisar $0,390-1,162$. Hasil penelitian Rahman dkk (2016) bahwa nilai indeks Diversitas fitoplankton di waduk Darma berkisar 0,78-0,81.

\section{Jenis - jenis zooplankton yang ditemukan pada waduk Darma}

Zooplankton, disebut juga plankton hewani, adalah hewan yang hidupnya mengapung, mengambang, atau melayang di air. Kemampuan renangnya sangat terbatas hingga keberadaanya sangat ditentukan oleh arus. Zooplankton bersifat heterotrofik, yakni tidak dapat memproduksi sendiri bahan organik dari anorganik. Oleh karena itu kelangsungan hidupnya sangat bergantung pada bahan organik dari fitoplankton sebagai makanannya. Ukurannya yang paling umum berkisar 0,2-2 mm (Nontji, 2006).

Tabel 5. Komposisi Zooplankton pada Stasiun 1

\begin{tabular}{lccc}
\hline \multicolumn{1}{c}{ Organisme } & A-1 & A-2 & A-3 \\
\hline ROTIFERA & & & \\
Brachionus sp. & 800 & 0 & 0 \\
Keratella sp. & 16.200 & 1.800 & 6.800 \\
Trichocerca sp. & 400 & 0 & 600 \\
Testudinella sp. & 0 & 200 & 0 \\
Notholca sp. & 1.600 & 0 & 1.000 \\
Polyarthra sp. & 0 & 0 & 400 \\
MALACOSTRACA & & & \\
Cyclops sp. & 200 & 400 & 0 \\
Calanus sp. & 8.000 & 3.600 & 11.000 \\
Daphnia sp. & 1.200 & 200 & 0 \\
Bosmina sp. & 0 & 0 & 2.000 \\
Canthocamptus sp. & 0 & 600 & 0 \\
Nauplius & 12.600 & 5.800 & 11.800 \\
\hline
\end{tabular}


Tabel 6. Komposisi Zooplankton pada stasiun 2

\begin{tabular}{lccc}
\hline \multicolumn{1}{r}{ Organisme } & B-1 & B-2 & B-3 \\
\hline ROTIFERA & 800 & 1.000 & 2.800 \\
Brachionus sp. & 1.200 & 1.000 & 1.600 \\
Keratella sp. & 600 & 400 & 600 \\
Trichocerca sp. & 200 & 0 & 0 \\
Platyias sp. & 400 & 0 & 0 \\
Kellicottia sp. & 0 & 0 & 200 \\
Notholca sp. & & & \\
CILIATA & 200 & 0 & 0 \\
Chilodonella sp. & & & \\
MALACOSTRACA & 400 & 1.800 & 1.400 \\
Cyclops sp. & 800 & 1.000 & 200 \\
Diaptomus sp. & 0 & 600 & 0 \\
Ceniodaphnia sp. & 1.200 & 400 & 0 \\
Canthocamptus sp. & 0 & 600 & 800 \\
Bosmina sp. & 0 & 400 & 0 \\
Limnocalanus sp. & 2.600 & 6.600 & 6.200 \\
Nauplius & &
\end{tabular}

Genera zooplankton yang keanekaragaman rendah. indeks ditemukan di stasiun 1 Waduk Darma selama penelitian sebanyak 12 genera yang mewakili 2 kelas, yaitu Rotifera dan Malacostraca. Jumlah masing-masing genera perkelas secara berturut-turut adalah 6 genera Rotifera dan 6 genera Malacostraca. Kelimpahan zooplankton berkisar $12.600-41.000 \mathrm{Sel} / \mathrm{m}^{3}$.

keseragaman berkisar 0,686 - 0,747 hal ini menunjukkan keseragaman tinggi, artinya penyebaran individu tersebut mendekati merata atau tidak ada spesies yang mendominasi. Nilai indeks dominansi berkisar 0,276 - 0,292 . Artinya tidak terdapat genus yang secara ekstrim mendominasi genus lainnya.

Dari Tabel 5 dapat dilihat bahwa indeks keanekaragaman zooplankton berkisar antara 1,379 - 1,454. Hal ini menunjukkan bahwa stasiun 1 memiliki tingkat

Genera zooplankton yang ditemukan di stasiun 2 Waduk Darma selama penelitian sebanyak 14 genera yang mewakili 3 kelas, yaitu Rotifera, ciliata

Tabel 7. Komposiși Zooplankton pada stasiun 3

\begin{tabular}{lccc}
\hline \multicolumn{1}{c}{ Organisme } & $\mathrm{C}-1$ & $\mathrm{C}-2$ & $\mathrm{C}-3$ \\
\hline ROTIFERA & 15.200 & 16.800 & 16.400 \\
Brachionus sp. & 9.800 & 8.200 & 12.800 \\
Keratella sp. & 400 & 12.000 & 8.200 \\
Trichocerca sp. & 0 & 0 & 200 \\
Euchlanis sp. & 2.200 & 5.400 & 2.200 \\
Rotania sp. & 200 & 200 & 0 \\
Notholca sp. & 1.200 & 0 & 0 \\
Polyarthra sp. & 0 & 1.400 & 9.400 \\
Kellicottia sp. & & & \\
CILlATA & 2.400 & 0 & 0 \\
Stylonychia sp. & 200 & 0 & 0 \\
Chilodonella sp. & & & \\
MALACOSTRACA & 14.400 & 8.800 & 16.400 \\
Cyclops sp. & 200 & 800 & 0 \\
Diaptomus sp. & 4.200 & 3.400 & 5.400 \\
Bosmina sp. & 0 & 400 & 0 \\
Limnocalanus sp. & 28.200 & 27.600 & 35.600 \\
Nauplius & & & \\
\hline
\end{tabular}

ın Perikanan dan Kelautan 
dan Malacostraca yang tersebar di seluruh kedalaman Jumlah masing-masing genera perkelas secara berturut-turut adalah 6 genera Rotifera, 1 genera Ciliata dan 7 genera Malacostraca. Kelimpahan zooplankton berkisar $8.400-13.800 \mathrm{Sel} / \mathrm{m}^{3}$.

Dari Tabel 6 dapat dilihat bahwa indeks keanekaragaman zooplankton berkisar antara 1,589 - 2,023. Hal ini menunjukkan bahwa stasiun 2 memiliki tingkat keanekaragaman rendah. indeks keseragaman berkisar 0,764-0,879 hal ini menunjukkan keseragaman tinggi, artinya penyebaran individu tersebut mendekati merata atau tidak ada spesies yang mendominasi. Nilai indeks dominansi berkisar 0,166 - 0,272 . Artinya tidak terdapat genus yang secara ekstrim mendominasi genus lainnya.

Genera zooplankton yang ditemukan di stasiun 3 Waduk Darma dan 5 genera Malacostraca. Kelimpahan zooplankton berkisar 78.600 - 106.600 $\mathrm{Sel} / \mathrm{m}^{3}$.

Dari Tabel 7 dapat dilihat bahwa indeks keanekaragaman zooplankton berkisar antara 1,755 - 1,877. Hal ini menunjukkan bahwa stasiun 3 memiliki tingkat keanekaragaman rendah. indeks keseragaman berkisar 0,706-0,842 hal ini menunjukkan keseragaman tinggi, artinya penyebaran individu tersebut mendekati merata atau tidak ada spesies yang mendominasi. Nilai indeks dominansi berkisar 0,190 - 0,220 . Artinya tidak terdapat genus yang secara ekstrim mendominasi genus lainnya.

Berdasarkan perhitungan persentase Zooplankton perkelas berturut-turut adalah $49 \%$ Rotifera, $44 \%$ Malacostraca dan 7\% Ciliata seperti yang terlihat pada gambar 3 .

Gambar 3. Persentase Zooplankton Di Waduk Darma

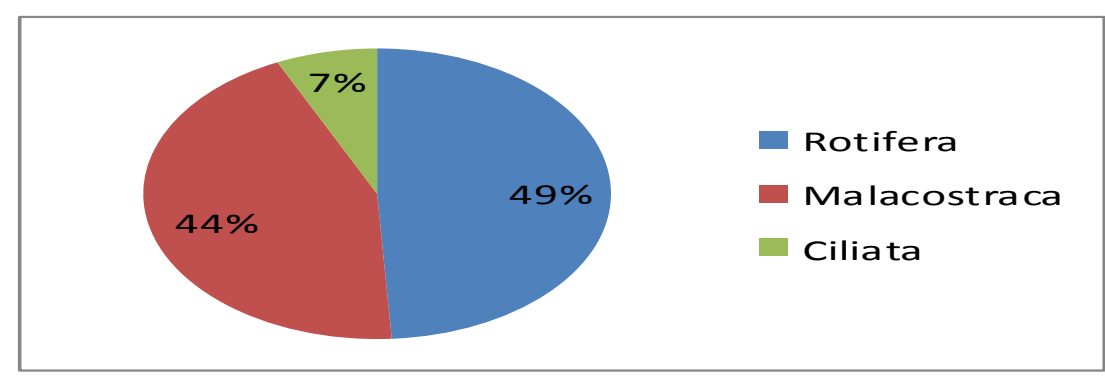

selama penelitian sebanyak 15 genera yang mewakili 3 kelas, yaitu Rotifera, ciliata dan Malacostraca . Jumlah masing-masing genera perkelas secara berturut-turut adalah 8 genera Rotifera, 2 genera Ciliata Volume 11 Nomor 3 Desember 2017
Diversitas (Tabel 8 ), nilai rata rata indeks Diversitas Zooplankton pada stasiun 1,2 dan 3 berkisar 1,419-1,827.

\section{B. Kondisi Perairan Waduk Darma}


Seperti halnya organisme hidup lain, plankton dalam pertumbuhan dan kehidupannya juga dipengaruhi oleh lingkungan. Oleh karena itu keberadaan plankton di perairan akan bervariasi tergantung dari kondisi kualitas perairan yang ada. Nilai pengukuran kondisi fisik dan kimiaWaduk Darma seperti pada Tabel 9.

Amonia $\left(\mathrm{NH}_{3}-\mathrm{N}\right)$

Kandungan amonia $\left(\mathrm{NH}_{3}-\mathrm{N}\right)$ pada perairan waduk Darma berkisar antara 0,343 - 0,560 mg/l Pada kondisi anaerobik senyawa organik nitrogen dirubah menjadi $\mathrm{N}-\mathrm{NH} 3$ yang pada konsentrasi tertentu bersifat racun terhadap organisme air. Goldman dan Horne (1983) menjelaskan terdapat perbedaan antara nitrat dan ammonia dalam hal toxisitas dan mobilitasnya. Dimana toxisitas ammonia aerobik maupun anaerobik (Welch 1980). Selain itu penggunaan N-NO3 membutuhkan penambahan energi seperti adanya enzim nitrat reduktase (Goldman \& Horne 1983). Senyawa-senyawa nitrogen sangat dipengaruhi oleh kandungan oksigen terlarut dalam air, pada saat kandungan oksigen rendah nitrogen berubah menjadi amoniak (NH3) dan saat kandungan oksigen tinggi nitrogen berubah menjadi nitrat (NO3-). Melalui proses nitrifikasi oleh bakteri Nitrosomonas sp dan Nitrobacter sp NNH3 diubah menjadi N-NO3

Nitrat $\left(\mathrm{NO}_{3}-\mathrm{N}\right)$

Kandungan nitrat $\left(\mathrm{NO}_{3}-\mathrm{N}\right)$ pada perairan waduk Darma berkisar antara $<0,001-0,269 \mathrm{mg} / \mathrm{l}$ Nitrat adalah sumber nitrogen dalam air laut maupun air tawar. Bentuk kombinasi lain dari elemen ini bisa tersedia dalam bentuk amonia, nitrit dan Tabel 8. Rata - Rata Indeks Diversitas Zooplankton

\begin{tabular}{ccc} 
Stasiun & Rata-Rata & Kisaran \\
\hline 1 & 1,419 & $1,379-1,454$ \\
2 & 1,794 & $1,589-2,023$ \\
3 & 1,827 & $1,755-1,877$ \\
\hline
\end{tabular}

lebih tinggi dari pada nitrat sedangkan komponen organik. Kombinasi elemen ini mobilitasnya lebih rendah dari pada nitrat. Pada umumnya nitrogen diabsorbsi oleh fitoplankton dalam bentuk nitrat (NO3-N) dan ammonia (NH3-N). Fitoplankton lebih banyak menyerap NH3-N dibandingkan dengan NO3-N karena lebih banyak dijumpai di perairan baik dalam kondisi sering dimanfaatkan oleh fitoplankton terutama kalau unsur nitrat terbatas. Nitrogen terlarut juga bisa dimanfaatkan oleh jenis blue-green algae dengan cara fiksasi nitrogen (Herawati,1989) Keberada an nitrat di perairan sangat dipengaruhi oleh buangan yang dapat berasal dari 
industri, bahan peledak, pirotekni, dan pemupukan. Secara alamiah kadar nitrat biasanya rendah namun kadar nitrat dapat menjadi tinggi sekali dalam air tanah di daerah yang diberi pupuk yang diberi nitrat/nitrogen (Alaerts, 1987). Nitrat adalah bentuk utama nitrogen di perairan alami dan merupakan nutrisi utama bagi pertumbuhan alga, yang dihasilkan dari proses oksidasi sempurna senyawa nitrogen di perairan (Effendi 2003). Nybakken (1988) melengkapi bahwa nutrien anorganik utama yang paling dibutuhkan fitoplankton untuk tumbuh dan berkembangbiak ialah nitrogen (dalam bentuk nitrat) dan fosfor (dalam bentuk fosfat).

Total Fosfat (PO4-P)

Kandungan fosfat (PO4-P) pada perairan waduk Darma berkisar antara 0,269 - 0,385 mg/l Fosfat merupakan berperan sebagai faktor pembatas bagi pertumbuhan organisma. Peningkatan konsentrasi fosfat dalam suatu ekositem perairan akan meningkatkan pertumbuhan algae dan tumbuhan air lainnya secara cepat. Peningkatan yang menyebabkan terjadinya penurunan kadar oksigen terlarut, diikuti dengan timbulnya anaerob yang menghasilkan berbagai senyawa toksik misalnya methan, nitrit dan belerang (Barus, 2001). Menurut Alaerts (1987), senyawa fosfat di perairan dipengaruhi oleh limbah penduduk, industri, dan perairan. Di daerah pertanian, dan persawahan fosfat berasal dari bahan pupuk yang masuk ke dalam sungai melalui drainase dan aliran air hujan. Secara umum ada tiga bentuk fosfor di ekosistem akuatik, yaitu fosfat terlarut, fosfor total terlarut dan fosfor partikulat. Fosfat di danau terdapat baik dalam Tabel 9. Hasil Pengukuran Kualitas Perairan Waduk Darma

\begin{tabular}{rcr} 
No & Paramater & Satu \\
1 & Amonia $\left(\mathrm{NH}_{3}-\mathrm{N}\right)$ & $\mathrm{mg} / \mathrm{L}$ \\
2 & Nitrat $\left(\mathrm{NO}_{3}-\mathrm{N}\right)$ & $\mathrm{mg} / \mathrm{L}$ \\
3 & Total Fosfat (PO4- & $\mathrm{mg} / \mathrm{L}$ \\
4 & P) & $\mathrm{mg} / \mathrm{L}$ \\
\hline
\end{tabular}

unsur yang sangat esensial sebagai bahan nutrien bagi berbagai organisme akuatik. Fosfat merupakan unsur yang penting dalam aktivitas pertukaran energi dari organisme yang dibutuhkan dalam jumlah sedikit (mikronotrien), sehingga fosfat

\begin{tabular}{cccc} 
atuan & \multicolumn{3}{c}{ Hasil } \\
$\mathrm{mg} / \mathrm{L}$ & 0,422 & 0,560 & St 3 \\
$\mathrm{mg} / \mathrm{L}$ & 0,269 & $<0.001$ & $<0.001$ \\
$\mathrm{mg} / \mathrm{L}$ & 0,338 & 0,385 & 0,269 \\
$\mathrm{mg} / \mathrm{L}$ & 3,2 & 3,7 & 3,3
\end{tabular}

organik maupun anorganik. Bentuk anorganik fosfat sebagian besar adalah ortofosfat (PO4-) dan sebagian lagi bentuk monofosfat (HPO4-) dan dihydrogenfosfat (H2PO4-) (Goldman dan Horne, 1983). 
Rahman,dkk (2016) melaporkan bahwa ortofosfat berpengaruh secara signifikan terhadap produktivitas primer di Waduk Darma. Input utama fosfor ke danau berasal dari aliran sungai dan pengendapan. Air hujan juga merupakan sumber fosfor namun hanya sedikit mengandung fosfor dari pada nitrogen. Sebagian besar fosfor terbawa ke danau yang tidak terpolusi sebagai partikel organik dan anorganik. Hampir setengah dari fosfor yang tekandung dalam limbah rumah tangga berasal dari detergen (Goldman dan Horne, 1983).

Nitrat dan fosfat merupakan unsur hara terpenting untuk pertumbuhan fitoplankton. Kadar nitrat dan fosfat yang optimal untuk pertumbuhan fitoplankton masing-masing 3,9 mg/l - 15,5 mg/l dan $0,27 \mathrm{mg} / \mathrm{l}-5,51 \mathrm{mg} / \mathrm{l}$. Nitrat dan fosfat merupakan faktor pembatas di bawah 0,144 mg/l dan 0,02 mg/l (Mackentum, 1969 dalam Haerlina, 1978).

BOD5

Kandungan BOD pada perairan waduk Darma berkisar antara 3,2 - 3,7 mg/l Pengukuran BOD didasarkan kepada kemampuan mikroorganisme untuk menguraikan senyawa organik, artinya hanya terdapat substansi yang mudah diuraikan secara biologis seperti senyawa yang umumnya terdapat dalam limbah rumah tangga (Barus, 2001). Menurut Brower, et al, (1990), nilai konsentrasi
BOD menunjukkan suatu kualitas perairan yang masih tergolong baik dimana apabila konsumsi $\mathrm{O} 2$ selama periode 5 hari berkisar sampai $5 \mathrm{mg} / \mathrm{l} \mathrm{O} 2$ maka perairan tersebut tergolong baik dan apabila konsumsi $\mathrm{O} 2$ berkisar antara $10 \mathrm{mg} / \mathrm{l}-20$ $\mathrm{mg} / \mathrm{l} \quad \mathrm{O} 2$ akan menunjukkan tingkat pencemaran oleh materi organik yang tinggi dan untuk air limbah nilai BOD umumnya lebih besar dari $100 \mathrm{mg} / \mathrm{l}$.

\section{SIMPULAN}

- Genera fitoplankton yang ditemukan di Waduk Darma sebanyak 19-32 genera yang mewakili 5 kelas, yaitu Chlorophyceae, Cyanophyceae, Bacillariophyceae, Dinophyceae dan Euglenaphyceae. Serta Genera Zooplankton yang ditemukan di Waduk Darma sebanyak 12-15 genera yang mewakili 3 kelas, yaitu Rotifera, Ciliata dan Malacostraca

- indeks keanekaragaman fitoplankton berkisar antara 0,390 - 1,162. Hal ini menunjukkan bahwa waduk Darma memiliki tingkat keanekaragaman rendah. indeks keseragaman berkisar $0,142-0,445$ hal ini menunjukkan keseragaman rendah, artinya penyebaran individu tersebut tidak merata atau ada spesies yang mendominasi. Nilai indeks dominansi berkisar $0,519-0,871$. berarti di dalam struktur komunitas biota yang diamati ter- 
dapat genus yang secara ekstrim mendominasi genus lainnya.

- Indeks keanekaragaman zooplankton berkisar antara $1,419-1,827$. Hal ini menunjukkan bahwa waduk Darma memiliki tingkat keanekaragaman rendah. indeks keseragaman berkisar $0,686-0,879$ hal ini menunjukkan keseragaman tinggi, artinya penyebaran individu tersebut mendekati merata atau tidak ada spesies yang mendominasi. Nilai indeks dominansi berkisar 0,166- 0,292. Artinya tidak terdapat genus yang secara ekstrim mendominasi genus lainnya.

- Kondisi perairan waduk Darma seperti ; fosfat $0,269-0,385$ $\mathrm{mg} / \mathrm{l}$; nitrat $<0,001-0,269 \mathrm{mg} / \mathrm{l}$; Amonia 0,343 - 0,560 mg/l; BOD $3,2-3,7 \mathrm{mg} / \mathrm{l}$

\section{DAFTAR PUSTAKA}

Alaerts, G.\& Sri, 1987. Metode Penelitian Air. Usaha Nasional, Surabaya.

Apdus. 2010. Analisis Kualitas Air Situ Bungur Ciputat Berdasarkan Indeks Keanekaragaman Fitoplankton. Jakarta: Skripsi Departemen Biologi UIN Syarif Hidayatullah
Barus, T. A. 2001. Pengantar Limnologi Studi Tentang Ekosistem Sungai dan Danau. Fakultas MIPA USU Medan.

Basmi, J. 2000. Planktonologi : Plankton Sebagai Bioindikator kualitas Perairan. Fakultas Perikanan dan Ilmu Kelautan. IPB. Hal : 40.

Brower, J. E., Jerrold H. Z., Car I.N. V. E.., 1990. Field and Laboratory Methods for General Ecology. Third Edition. Wm. C. Brown Publisher, USA, New York

Effendi H. 2003. Telaah Kualitas Air Bagi pengelolahan Sumberdaya dan Lingkungan Perairan. Bogor: Penerbit Kanasius

Goldman, C. R. and A. J. Horne. 1983. Limnology. McGraw-Hill Book Company. United State of America. America

Haerlina. E. 1987. Komposisi dan Distribusi Vertikal Darian Fitoplankton Pada Siang dan Malam Hari di Perairan Pantai Bojonegoro, Teluk Banten. Fakultas Perikanan, IPB Bogor

Herawati, E.Y. 1989. Pengantar Planktonologi (fitoplankton). NUFFIC/UNIBRAW/ LUW/ FISH. Universitas Brawijaya. Malang

Lukman, Sulastri, D.S. Said, T. Tarigan, dan T. Widiyanto. 2006. Prosiding Seminar Nasional Limnologi 2006 "Pengelolaan Sumberdaya Perairan Darat secara Terpadu di Indonesia. Pusat Penelitian Limnologi-LIPI. Bogor

Mason, C.F. 1981. Biology of Fresh Water Pollution. Longman. New York. 
Michael, P. (1984). Ecological nretlrods lor field and laboratory investigations.'lata McGraw-Hill Publishing Conrpany, LJSA.

Nursa'ban, 2008. Evaluasi Sediment Yield di daerah aliran Sungai Cisanggarung bagian Hulu dalam memperkirakan sisa unsur Waduk Darma. Universitas Negeri Yogyakarta. Yogyakarta

Nontji, A. 2006. Tiada Kehidupan di Bumi Tanpa Keberadaan Plankton. Lembaga Ilmu Pengetahuan Indonesia. Pusat Penelitian Oseanografi. Jakarta

Nyibakken, J.W. 1988. Biologi Laut. Suatu Pendekatan Ekologis. Penerbit PT.Gramedia. Jakarta

Odum, E.P. 1971.Fundamental Ecology 3 rd. W.B. Sanders Company. Philadelphia, 574 pp

Rahman,E.C., Masyamir dan Rizal A. 2016. Kajian Variabel Kualitas Air Dan Hubungannya Dengan Produktifitas Primer Fitoplankton Di Perairan Waduk Darma Jawa Barat. Jurnal Perikanan Kelautan Vol. VII No. 1/Juni 2016 (93-102).

Welch EB. 1980. Ecological Effect of Waste Water. Cambridge: Cambridge University Press

Wiadnya, D. G., Sutini L., dan Lelono T.F. 1993. Manajemen Sumberdaya Perairan Dengan Kasus Perikanan Tangkap di Jawa Timur. Fakultas Perikanan. Universitas Brawijaya. Malang 